\title{
Asymmetric Interaction of Optically Active Polymers with Asymmetric Small Molecules. II. Interaction of Optically Active Basic Polymers with Tryptophan
}

\author{
Yasuji Ihara, Joichi Koga, and Nobuhiko KurokI \\ Department of Applied Chemistry, University of Osaka \\ Prefecture, Mozu-Umemachi, Sakai, Osaka, Japan.
}

(Received August 5, 1971)

\begin{abstract}
In order to obtain precise information about the possibility of optical resolution of $\alpha$-amino acids on optically active polymers, optically active basic polymers were prepared from $N$-phthalyl-L-glutamyl chloride and diamines such as hexamethylenediamine, $p$-phenylenediamine, benzidine, and 1,5-naphthalenediamine respectively, followed by hydrazinolysis. The adsorption and binding behavior of $\mathrm{D}$ - and L-tryptophan on these polymers were then investigated. It has been found from the investigation that the amounts of L-isomer bound to the polymers are greater than the amounts of D-isomer. In the case of the polymer containing a naphthalene group, the difference in the degree of adsorption between the optical isomers is greatest, while in the case of the polymer containing a hexamethylene group, that is smallest. From the results in the present investigation it is concluded that the polymers containing L-amino acid adsorb L-amino acid preferentially and the introduction of aromatic diamines increases the difference in adsorption behaviors between optical isomers but the introduction decreases the adsorption capacity.
\end{abstract}

KEY WORDS Asymmetric Interaction / Optically Active Polymer / Asymmetric Small Molecule / D- and L-Tryptophan /

Optical resolution of organic compounds on biopolymers such as polysaccharides, wool, and casein has been reported. ${ }^{1-4}$ However, the resulting optical activities of these compounds are usually very low and the adsorption capacity of the polymers is very small. Recently, the resolution methods of racemates on synthetic optically active polymers have been developed, ${ }^{5-7}$ however, a clear relationship between the structure of the polymers and their asymmetric interaction has not been found. In these methods, the effective resolution can only be observed when there is an adequate degree of combination between the polymer and an asymmetric substance.

The purpose of this study is to obtain precise information about the mechanism of the asymmetric interaction between optically active polymers and asymmetric molecules and to investigate the possibility of optical resolution of $\alpha$-amino acids on synthetic polymers.
In the author's previous investigation, ${ }^{8}$ optically active acidic polymers were synthesized from L-lysine and acid chlorides by the interfacial polycondensation method, and interactions of these polymers with amino acids were investigated. The results have shown that the L-form of amino acids is apparently bound more than the D-form.

In the present investigation, optically active polymers having $-\mathrm{NH}_{2}$ groups (B polymer) were prepared and the interactions of these polymers with tryptophan studied. The structure of the B polymer was designed on the basis of the following ideas themselves based on the classical method of resolution of enantiomers normally achieved by the formation of diastereoisomers.

(1) The polymer should be stable in water.

(2) The polymer should contain ionic groups so that they are able to form ionic bonds with small ionic molecules and the ionic groups should be located near the asymmetric centers of the polymer. 
(3) The polymer should contain hydrophobic regions which increase the adsorption affinity of asymmetric small molecules.

\section{EXPERIMENTAL}

\section{Preparation of the Optically Active Polymers}

The synthesis route for B polymer is shown in Scheme 1.

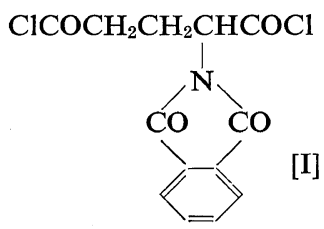

Glu. $\underset{\text { phthalimide }}{\stackrel{N \text {-Carboethoxy- }}{\longrightarrow} \text { Phthalyl glu. }}$
$\stackrel{\mathrm{PC}_{5}}{\longrightarrow}$ Phthalyl-glutamyl-chloride

[I]

$[\mathrm{I}]+\mathrm{H}_{2} \mathrm{NRNH}_{2} \stackrel{-\mathrm{HCl}}{\longrightarrow}$ Phthalyl polymer

$\underset{\text { EtOH }}{\stackrel{\mathrm{H}_{2} \mathrm{NNH}_{2} \cdot \mathrm{H}_{2} \mathrm{O}}{\longrightarrow}}$ B Polymer

[II]

$\mathrm{R}: \mathrm{B}-1,-\left(\mathrm{CH}_{2}\right)_{6}-$<smiles>[R18]c1ccc(C)cc1</smiles><smiles>[R5]c1ccc(-c2ccc(C)cc2)cc1</smiles>

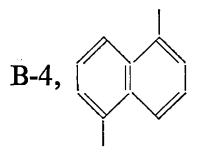

Scheme 1

Phthalylglutamic acid has already been prepared from glutamic acid by treating it with phthalic anhydride by the fusion method. ${ }^{9}$ However, the reaction conditions in this method were so drastic that partial racemization took place during the reaction. The optically pure $N$-phthalyl L-glutamic acid was therefore prepared from L-glutamic acid and $N$-carboethoxyphthalimide by the method described by Nefkens, et $a .^{10}$ Phthalyl L-glutamic acid was converted to $N$-phthalyl glutamyl chloride [I] by treating with phosphorus pentachloride in chloroform. The product $[\mathrm{I}]$ was reacted with diamines such as hexamethylene diamine, $p$-phenylene diamine, benzidine, and 1,5-naphthalene diamine respec-

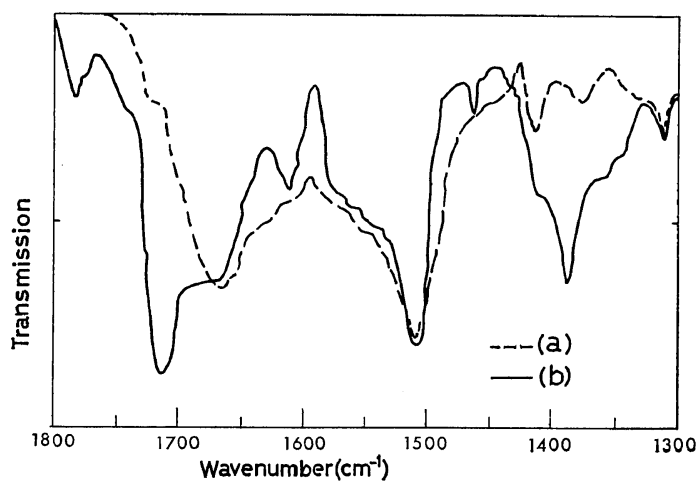

Figure 1. Infrared absorption spectra of B-2 polymer(a) and its phthalyl polymer(b).

tively to give the polyamide of phthalyl glutamic acid by interfacial polycondensation or low temperature polycondensation methods. By treatment of the phthalyl polymers with hydrazine hydrate in ethanol, the corresponding $\mathbf{B}$ polymer was obtained.

Figure 1 shows the infrared absorption spectra of B-2 polymer and its phthalyl polymer. As is evident from comparison of both polymers in Figure 1, the phthalyl polymer showed absorption bands of $\mathrm{C}=\mathrm{O}$ of the phthalyl group at 1720 and $1775 \mathrm{~cm}^{-1}$ and a typical amide linkage at $1660 \mathrm{~cm}^{-1}$, while B-2 polymer showed a single absorption at $1658 \mathrm{~cm}^{-1}$.

From the results of elemental analyses of $\mathbf{B}$ polymer, it is likely that the hydrazinolysis was done completely.

B-1 is a water soluble polymer and was used for dialysis experiments. B-2, B-3, and B-4 are insoluble, but are soluble in acidic solution. These three polymers were lightly crosslinked with 2,4-toluene diisocyanate to make the polymers insoluble and stable in aqueous solution. In the binding and adsorption experiments these polymers were used.

These crosslinked polymers were still soluble in dimethyl sulfoxide (DMSO). The viscosities in DMSO of the crosslinked polymers obtained in this manner were greater than those of the unreacted polymers. The specific optical rotation of crosslinked polymers showed similar values as those of their related linear polymers.

$N$-Phthalyl-L-glutamic Acid. $N$-Phthalyl-L-glutamic acid was prepared from L-glutamic acid 
Asymmetric Interaction of Optically Active Polymers with Asymmetric Small Molecules. II.

and $N$-carboethoxyphthalimide by the method described by Nefkens, et al.: yield, 56\%, mp $159-160^{\circ} \mathrm{C} ;[\alpha]_{\mathrm{D}}^{22}=-48.3^{\circ}$ ( $c=3$ in dioxane).

$N$-Phthalyl-L-glutamyl Chloride [I]. N-PhthalylL-glutamyl chloride was prepared from phthalylL-glutamic acid and phosphorous pentachloride by the same method as described for $\mathrm{D}-$ and DL-mixture by Koda, et al.: ${ }^{11}$ yield, $67 \%, \mathrm{mp}$ $56-58^{\circ} \mathrm{C} ;[\alpha]_{\mathrm{D}}^{18}=-40.1^{\circ} \quad(c=2$ in chloroform $)$. Anal. Calcd for $\mathrm{C}_{13} \mathrm{H}_{9} \mathrm{NO}_{4} \mathrm{Cl}_{2}: \mathrm{C}, 49.68 ; \mathrm{H}, 2.87$; N, 4.46. Found: C, 49.30; H, 2.91; N, 4.23.

\section{Phthalyl Polymers}

Poly(hexamethylene $N$-phthalyl-L-glutamyl)amide [II-1]. To a solution of $7 \mathrm{~g}(0.06 \mathrm{~mol})$ of hexamethylenediamine in $280 \mathrm{ml}$ water, $12.8 \mathrm{~g}$ of sodium carbonate was added. The mixture was cooled to $5-10^{\circ} \mathrm{C}$ and then a solution of $18.9 \mathrm{~g}$ $(0.06 \mathrm{~mol})$ of $N$-phthalyl-L-glutamyl chloride [I] in $150 \mathrm{ml}$ of dry chloroform was added quickly. The mixture was vigorously agitated for $30 \mathrm{~min}$. After the reaction, the mixture was acidified with dil. hydrochloric acid, the precipitated polymer was filtered, washed with water and dried: yield, $21 \mathrm{~g} \mathrm{(98 \% );} \mathrm{mp} 160-170^{\circ} \mathrm{C},[\alpha]_{\mathrm{D}}^{23}=-11.2^{\circ}$ $\left(c=2\right.$ in DMF); $\eta_{\mathrm{sp}} / c=0.270$ ( $c=0.5$ in DMF, $\left.25^{\circ} \mathrm{C}\right)$.

Poly(p-phenylene $N$-phthalyl-L-glutamyl)amide [II-2]. To a solution of $10.8 \mathrm{~g}(0.1 \mathrm{~mol})$ of $p$ phenylenediamine in $400 \mathrm{~m} l \mathrm{THF}, 20.2 \mathrm{~g}(0.2 \mathrm{~mol})$ of triethylamine was added. The mixture was cooled to $-5-0^{\circ} \mathrm{C}$ and then a solution of $31.4 \mathrm{~g}$ $(0.1 \mathrm{~mol})$ of [I] in $80 \mathrm{ml}$ of THF was added slowly. After one hour at room temperature, the reaction mixture was concentrated under reduced pressure until a volume of $200 \mathrm{ml}$ remained. This was poured into $1 l$ water with vigorous stirring. The precipitated polymer was collected, washed with water and dried: yield, $32.4 \mathrm{~g} \quad(93 \%) ; \operatorname{mp~} 150-152^{\circ} \mathrm{C} ; \quad[\alpha]_{\mathrm{D}}^{23}=-55.5^{\circ}$ $\left(c=2\right.$ in DMF); $\eta_{\mathrm{sp}} / c=0.223$ ( $c=0.5$ in $\mathrm{DMF}$, $\left.25^{\circ} \mathrm{C}\right)$.

Poly(benzidine N-phthalyl-L-glutamyl)amide [II3]. Benzidine and [I] were treated in the same way as [II-2]: yield, 98\%; $\mathrm{mp} 260-268^{\circ} \mathrm{C}$; $[\alpha]_{\mathrm{D}}^{23}=-77.8^{\circ}(c=2$ in DMF $) ; \eta_{\mathrm{sp}} / c=0.200(c=$ 0.5 in DMF, $\left.25^{\circ} \mathrm{C}\right)$.

Poly(1,5-naphthalene $N$-phthalyl-L-glutamyl) amide $[I I-4] . \quad 1,5$-Naphthalenediamine and $[\mathrm{I}]$ were treated in the same way as [II-2]: yield, 95\%; $\mathrm{mp} 212-218^{\circ} \mathrm{C} ;[\alpha]_{\mathrm{D}}^{23}=-56.1^{\circ} \quad(c=2$ in $\mathrm{DMF}) ; \eta_{\mathrm{sp}} / c=0.181\left(c=0.5\right.$ in DMP, $\left.25^{\circ} \mathrm{C}\right)$.

\section{Cleavage of Phthalyl Group with Hydrazine Hydrate}

B-1 Polymer. To a suspention of $17.9 \mathrm{~g}$ of [II-1] in $200 \mathrm{ml}$ ethanol, $5.9 \mathrm{~g}$ of $85 \%$ hydrazine hydrate was added at $50^{\circ} \mathrm{C}$ under nitrogen atmosphere. After two hours, the mixture was filtered and the filtrate was concentrated to dryness under reduced pressure. The residual solid was dissolved in water and $6 N$-hydrochloric acid added to this solution. The precipitated phthalhydrazide was removed by filtration. The filtrate was dialyzed and freeze-dried, and $5.5 \mathrm{~g}$ of B-1 polymer hydrochloride was obtained, $\mathrm{mp}$ $138-143^{\circ} \mathrm{C}$. Anal. Calcd for $\left(\mathrm{C}_{11} \mathrm{H}_{22} \mathrm{~N}_{3} \mathrm{O}_{2} \mathrm{Cl}\right)_{n}$ : C, $50.09 ; \mathrm{H}, 8.35 ; \mathrm{N}, 15.94$. Found: C, 50.89; $\mathrm{H}, 8.78 ; \mathrm{N}, 15.47$.

B-2 Polymer. To a suspention of $28.0 \mathrm{~g}$ of [II-2] in $320 \mathrm{ml}$ ethanol, $9.5 \mathrm{~g}$ of $85 \%$ hydrazine hydrate was added, and then the mixture was heated at $70^{\circ} \mathrm{C}$ for two hours. The reaction mixture was allowed to stand for two hours at room temperature. The product was filtered, washed thoroughly with diluted aqueous ammonia and with water, and dried: yield, $16.5 \mathrm{~g}$; $\mathrm{mp} 156-164^{\circ} \mathrm{C} ;[\alpha]_{\mathrm{D}}^{23}=+13.5^{\circ}(c=2$ in DMSO $)$; $\eta_{\mathrm{sp}} / c=0.153\left(c=0.5\right.$ in DMSO, $\left.25^{\circ} \mathrm{C}\right)$. Anal. Calcd for $\left(\mathrm{C}_{11} \mathrm{H}_{13} \mathrm{~N}_{3} \mathrm{O}_{2}\right)_{n}: \mathrm{C}, 60.27 ; \mathrm{H}, 5.94 ; \mathrm{N}$, 19.18. Found: C, 61.13; H, 5.55; N, 18.71.

B-3 Polymer. Phthalyl polymer [II-3] was treated with hydrazine hydrate in the same way as B-2: $\mathrm{mp} 191-194^{\circ} \mathrm{C} ;[\alpha]_{\mathrm{D}}^{23}=+16.5^{\circ}(c=2$ in DMSO); $\eta_{\mathrm{sp}} / c=0.139\left(c=0.5\right.$ in DMSO, $\left.25^{\circ} \mathrm{C}\right)$. Anal. Calcd for $\left(\mathrm{C}_{17} \mathrm{H}_{17} \mathrm{~N}_{3} \mathrm{O}_{2}\right)_{n}: \mathrm{C}, 69.15, \mathrm{H}$, 5.76; N, 14.24. Found: C, 70.02; H, 5.58; N, 13.93.

B-4 Polymer. Phthalyl polymer [II-4] was treated with hydrazine hydrate in the same way as B-2: $\mathrm{mp} 186-189^{\circ} \mathrm{C} ;[\alpha]_{\mathrm{D}}^{23}=+5.3^{\circ} \quad(c=2$ in DMSO); $\eta_{\mathrm{sp}} / c=0.131\left(c=0.5\right.$ in DMSO, $\left.25^{\circ} \mathrm{C}\right)$. Anal. Calcd for $\left(\mathrm{C}_{15} \mathrm{H}_{15} \mathrm{~N}_{3} \mathrm{O}_{2}\right)_{n}$ : C, 66.91; $\mathrm{H}$, 5.58; N, 15.61. Found: C, 67.25, H, 5.39; N, 15.25 .

Crosslinking of Polymers. $15 \mathrm{~g}$ of B-2 polymer was dissolved in $150 \mathrm{~m} l$ of DMSO and then $0.3 \mathrm{~g}(2 \%)$ of 2,4-toluene diisocyanate was added. 
The mixture was stirred at $50^{\circ} \mathrm{C}$ for one hour. After filtration, the filtrate was poured into $1.5 l$ of water with vigorous stirring. The precipitated product was collected, washed with water thoroughly and dried: yield, $9.3 \mathrm{~g}$.

B-3 and B-4 polymers were crosslinked in the same way as B-2.

\section{Adsorption Experiments}

In a typical adsorption experiment $0.5 \mathrm{~g}$ of crosslinked polymer was immersed in $20 \mathrm{ml}$ of a buffer solution containing a certain amount of an amino acid. After 45 hours of shaking at $25^{\circ} \mathrm{C}$, the polymer was removed and the amount of bound tryptophan was measured by a spectrophotometric method.

\section{Dialysis Experiments}

For the equilibrium-dialysis experiments, cellophane bags (Visking Company) were washed with hot water to remove any water-soluble impurities. The bags were filled with a measured amount of B-1 polymer in buffer solution. Each bag was immersed in a solution of tryptophan and was placed in an incubator at $25^{\circ} \mathrm{C}$. The immersion was maintained for 64 hours. After the bags were removed, the concentration of the compounds was measured spectrophotometrically. In the preliminary experiment, it was found that binding of the compounds to the cellophane membranes was negligible.

\section{Spectrophotometric Measurements}

With a Hitachi Spectro-photometer, Model ESS-3T, the light absorption was measured at approximatelly $25^{\circ} \mathrm{C}$. After the adsorption or dialysis experiment a $\lambda_{\max }$ of the internal solution of the bound compound was measured by using the external solution as a reference so that the apparent absorption could be regarded only as absorption of the bound compound.

\section{RESULTS AND DISCUSSION}

In the authors' previous investigation, ${ }^{8}$ it was found that the optically active acidic polymers (A polymer) synthesized from L-lysine and dichlorides of dicarboxylic acids such as adipic, terephthalic, 4,4'-diphenyldicarboxylic, and 2,6naphthalenedicarboxylic acids, adsorbed L-from of amino acids preferentially better than their D-form. In this investigation, a study was made

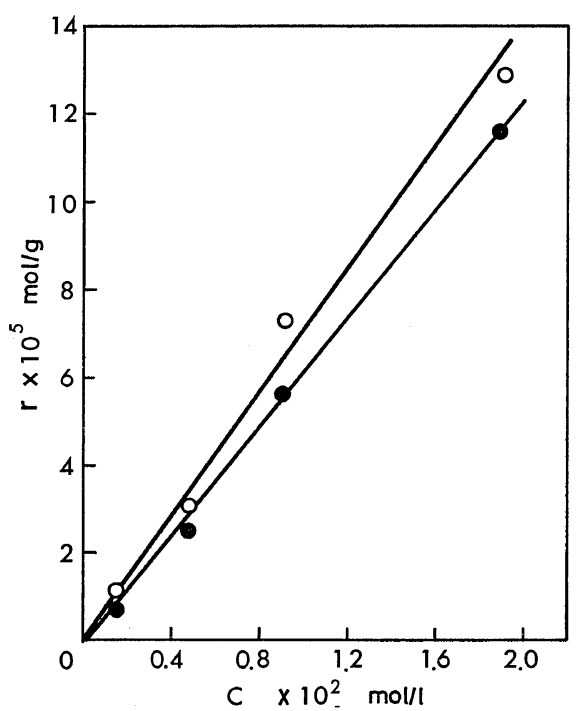

Figure 2. Adsorption of $\mathrm{D}-(-)$ and $\mathrm{L}-(\mathrm{O})$ tryptophan on $\mathrm{B}-2$ polymer at $\mathrm{pH} 5.7,25^{\circ} \mathrm{C}$.

of the asymmetric interaction of basic polymers (B-1, B-2, B-3, and B-4) and optically active tryptophan.

Figure 2 shows the results of the isothermal adsorption of D- and L-tryptophan on B-2 polymer at $\mathrm{pH} 5.7,25^{\circ} \mathrm{C}$. The degree of adsorption is represented as the moles of adsorbed tryptophan per gram of polymer, $r v s$. the concentration of the free tryptophan, $\mathrm{C}(\mathrm{mol} / \mathrm{l})$.

As shown in Figure 2 it is apparent that the amount of L-form adsorbed on B-2 polymer is greater than the amount of D-form. It is worthnoting that in the previous experiment the Lform of tryptophan was also preferentially adsorbed on the acidic polymers. All of the basic polymers in the present investigation adsorbed L-tryptophan preferentially rather than D-tryptophan (discussed later). Roberts and Haigh ${ }^{5}$ have reported the resolution of DL-methionine on poly[S-(ar-vinylbenzyl)-L-cysteine $]$ H. Suda, et $a l^{7}$ have prepared poly $(N$-acrylyl-L-pyroglutamic acid) and have studied on the optical resolution of $\alpha$-amino acids on the polymer. And the results have indicated that L-isomers of the amino acids adsorb selectively on the polymer. It therefore appears that polymers which made of $\alpha$-amino acids in the L-configuration adsorb the L-form of amino acids preferentially.

To evaluate the influence of the introduction 
Asymmetric Interaction of Optically Active Polymers with Asymmetric Small Molecules. II.

of biphenylene and naphthalene groups respectively into the basic polymers on asymmetric interaction behavior, isothermal adsorption experiments were also carried out. The results of the isothermal adsorption of $\mathrm{D}$ - and L-tryptophan on B-3 and B-4 polymers are presented in Figures 3 and 4, respectively. As is apparent from Figures 3 and 4, the introduction of a larger aromatic ring into the monomer unit resulted in an increase in the difference in adsorption behavior between L- and D-tryptophan. The adsorption capacities of B-3 and B-4 polymers are smaller than that of B-2 polymer. These phenomena may be interpreted in terms of the crystallinities of the polymers. It is well known in the dyeing chemistry that dyeing sites are available only in the amorphous region of fibers. As B-3 and B-4 polymers are presumably highly crystallized compared to B-2 polymer, small molecules are not able to enter into the inside

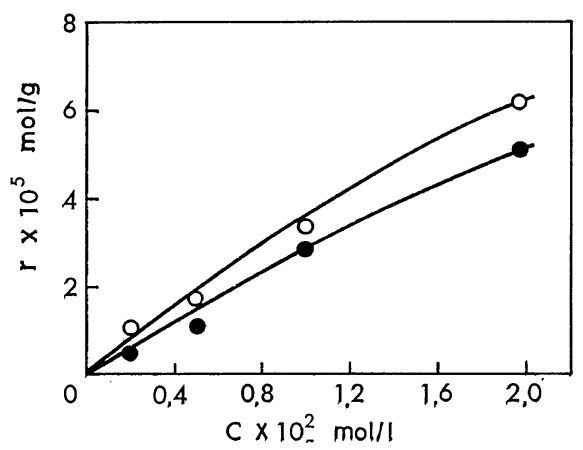

Figure 3. Adsorption of $\mathbf{D}-(\mathbf{O})$ and $\mathrm{L}-(\mathrm{O})$ tryptophan on $\mathrm{B}-3$ polymer at $\mathrm{pH} 5.7,25^{\circ} \mathrm{C}$.

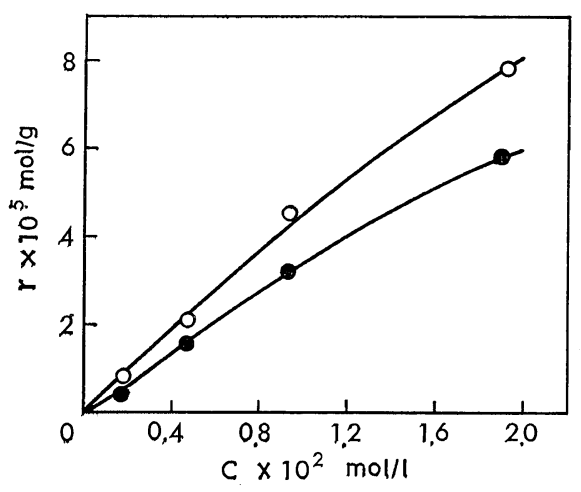

Figure 4. Adsorption of $\mathrm{D}-(\bigcirc)$ and $\mathrm{L}-(\mathrm{O})$ tryptophan on $\mathrm{B}-4$ polymer at $\mathrm{pH} 5.7,25^{\circ} \mathrm{C}$.

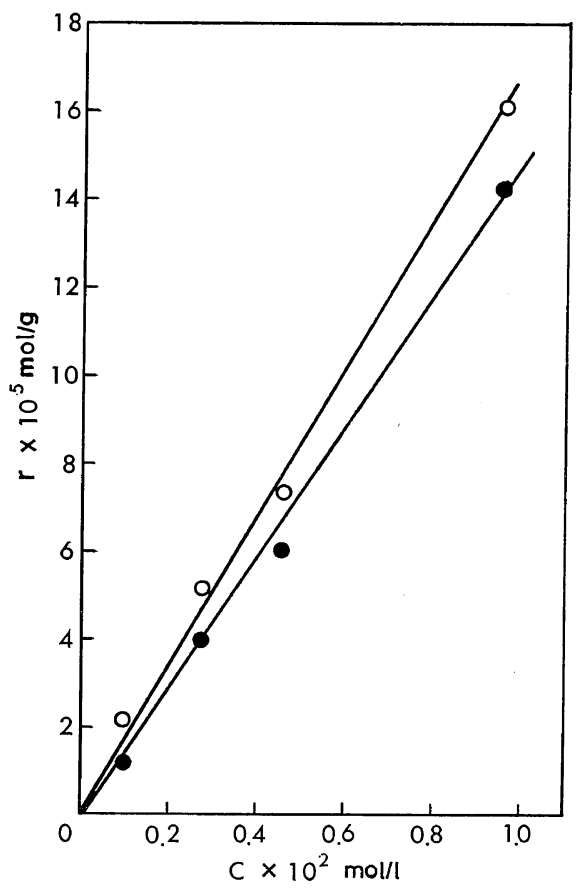

Figure 5. Binding of $\mathrm{D}-(-)$ and $\mathrm{L}-(\bigcirc)$ tryptophan to $\mathrm{B}-1$ polymer at $\mathrm{pH} 5.4,25^{\circ} \mathrm{C}$.

of the polymer. With this fact in mind, the equilibrium adsorption of tryptophan onto B-1 polymer was carried out by the dialysis technique. In Figure 5 the binding isotherms of D- and Ltryptophan at $\mathrm{pH} 5.4,25^{\circ} \mathrm{C}$ are shown.

The amounts of the bound compounds of both D- and L-tryptophan on B-1 polymer are greater than those on the other polymers as would be expected. The binding isotherms of tryptophan on B-1 polymer show straight lines. These facts suggest that transfer of the compounds from an aqueous solution to the organic polymer may occur in this case. The difference between the optical isomers in binding behavior is small but significant, and L-isomer binds preferentially on the polymer as is observable on the other polymers.

To evaluate the resolving ability of each polymer, the binding constants of $\mathrm{D}$ - and Ltryptophan with each polymer were calculated. Interaction of the polymer molecule with small molecules usually involves a multiple-binding process in which the polymer interacts simultaneously with more than one small molecule. 
The molecule exerts no electrostatic influence on the succeeding bindings, and all of the molecules bind with the same type of group on the polymer. In such a case the strength of attachment is the same for each bound molecule. $\mathrm{Klotz}^{12}$ has derived an equation, eq 1 , in which $r$ represents the moles of compounds bound per gram polymer: $n$ is a total number of available binding sites on polymer: $K$ is the intrinsic binding constant, and $c$ is the concentration of free small molecule.

$$
\frac{1}{r}=\frac{1}{n K} \frac{1}{c}+\frac{1}{n}
$$

The relative values of the successive equilibrium constants can be determined solely by statistical factors. For this situation the equilibrium constant of $i$-th reaction is given by the relation:

$$
k_{i}=\frac{n-(i-1)}{i} K
$$

For the first reaction $(i=1)$, the first equilibrium constant, $k_{1}$ is equal to $n K$ in eq 2 . With B-1 and B-2 polymers the linearity of $r v s . c$ plot (Figures 2 and 5) implies that $K c \ll 1$ in eq 1 . However, the intercept is neglegible, so that $n$ could be very large. If $n K$ is the degree of the binding, its value is obtained from plots of $1 / r$ vs. $1 / c$. In Figure 6 , the relative affinities of D- and L-tryptophan for B-2 polymer are shown.

As shown in Figure 6, a linear relationship between $1 / r$ and $1 / c$ is obtained. For each polymer, the same relationship is obtained as

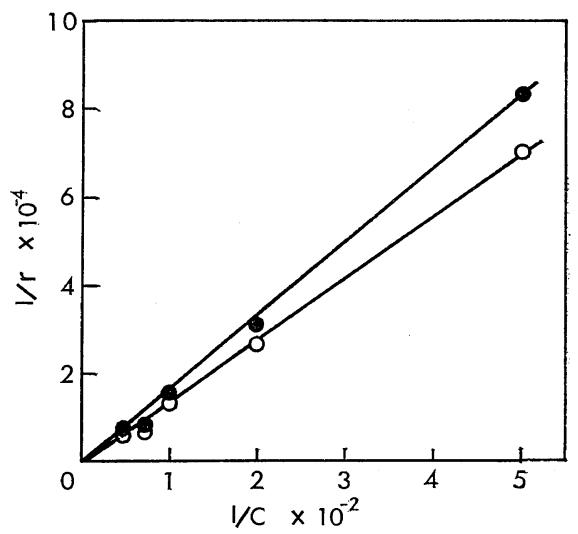

Figure 6. Adsorption affinities of $\mathrm{D}-(-)$ and L(O) tryptophan for $\mathrm{B}-2$ polymer at $\mathrm{pH} 5.7,25^{\circ} \mathrm{C}$.
Table I. Values of $n K$ of the D- and L-tryptophan for each polymer at $\mathrm{pH} 5.4-5.7,25^{\circ} \mathrm{C}$

\begin{tabular}{cccc}
\hline & \multicolumn{2}{c}{$n K\left(1 / g \times 10^{3}\right)$} & $n$ \\
\cline { 2 - 3 } Polymer & $\mathrm{L}$ & $\mathrm{D}$ & \\
\hline $\mathrm{B}$ & 17.2 & 15.2 & 1.13 \\
$\mathrm{~B}-1$ & 7.16 & 5.92 & 1.21 \\
$\mathrm{~B}-2$ & 3.85 & 2.98 & 1.29 \\
$\mathrm{~B}-4$ & 4.98 & 3.43 & 1.45 \\
\hline
\end{tabular}

was found for B-2 polymer. Table I summarizes values of $n K$ for $\mathrm{D}$ - and L-tryptophan and the ratio of $n K$ of the D-isomer and L-isomer, $n K_{\mathrm{L}} / n K_{\mathrm{D}}$.

The values of $n K$ in Table I do not give directly binding affinites (the intrinsic binding constant) of tryptophan to the polymers, because in each experimental result the values of $n$ are different. For instance, binding isotherms for B-1 and B-2 polymers show straight lines representing the fact that their apparent $n$ values are infinite. Such large $n$ values suggest transfer of the tryptophan from an aqueous solution to the organic polymers as mentioned before. Even though binding affinities of tryptophan to the polymers cannot be compared, a comparison of asymmetric binding affinities $\left(n K_{\mathrm{L}} / n K_{\mathrm{D}}\right)$ of optically active tryptophan to the polymers can be made. Asymmetric selectivity of binding of optically active tryptophan to the polymers increases when a large aromatic ring is substituted in a monomer unit. In the case of the polymer containing a naphthalene group, $n K_{\mathrm{L}} / n K_{\mathrm{D}}$ is greatest, while in the case of the polymer containing a hexamethylene group, $n K_{\mathrm{L}} / n K_{\mathrm{D}}$ is smallest. Although the mechanism of the asymmetric binding is not entirely clear at the present time, the effect of aromatic rings in opticylly active polymers seems to be playing an important role the asymmetric binding of tryptophan.

\section{REFERENCES}

1. G. M. Henderson and H. G. Rule, J. Chem. Soc., 1568 (1939).

2. H. Krebs, J. Diewald, and J. A. Wagner, Chem. Ber., 89, 1857 (1956).

3. W. Bradley and G. C. Easty, J. Chem. Soc., 499 (1951).

4. W. Bradley and G. C. Easty, ibid., 1519 (1953). 
Asymmetric Interaction of Optically Active Polymers with Asymmetric Small Molecules. II.

5. C. W. Roberts and D. H. Haigh, J. Org. Chem., 27., 3377 (1962).

6. T. Yamashita and N. Nakamura, Bull. Chem. Soc. Japan, 43, 1809 (1970).

7. H. Suda, Y. Hosono, Y. Hosokawa, and T. Seto, Kogyo Kagaku Zasshi (J. Chem. Soc. Japan, Chem. Ind. Sect.), 73, 186 (1970).

8. Y. Ihara, J. Koga and N. Kuroki, J. Polym. Sci., Part A-1, 9, 2413 (1971).
9. Y. Matsumoto, M. Shirai, and M. Minagawa, Bull. Chem. Soc., Japan, 40, 1650 (1967).

10. G. H. L. Nefkens, G. I. Tesses, and R. J. F. Nivard, Rec. Trav. Chim., 79, 688 (1960).

11. Y. Koda, T. Shono, and Y. Hachihama, Kogyo Kagaku Zasshi, (J. Chem. Soc. Japan, Chem. Ind. Sect.), 66, 1513 (1963).

12. L. Klotz, F. Walker, and R. Pivan, J. Amer. Chem. Soc., 68, 1486 (1946). 